\title{
Atividade antibacteriana in vitro de pimentas e pimentões (Capsicum sp.) sobre quatro bactérias toxinfectivas alimentares
}

\author{
CARVALHO, H.H.*; WIEST, J.M.; CRUZ, F.T. \\ Instituto de Ciência e Tecnologia de Alimentos/Universidade Federal do Rio Grande do Sul -ICTA/UFRGS, Av. \\ Bento Gonçalves, 9500, Campus do Vale/Agronomia, Caixa Postal 15090, CEP:91505-970, Porto Alegre-Brasil \\ *hhcarvalho@terra.com.br
}

\begin{abstract}
RESUMO: Determinou-se in vitro a Intensidade de Atividade de Inibição Bacteriana (IINIB) e a Intensidade de Atividade de Inativação Bacteriana (IINAB), através de Testes de Diluição em Sistema de Tubos Múltiplos, de extratos de oito pimentas do gênero Capsicum, etnograficamente acessadas na região metropolitana de Porto Alegre/RS/BR, frente a inóculos bacterianos padronizados (American Type Culture Collection-ATCC), respectivamente Staphylococcus aureus (25923), Enterococcus faecalis (19433), Salmonella enteritidis (13076) e Escherichia coli (11229), em doses-desafio $=10^{7}$ UFC mL-1. Quatro destas plantas, pimenta calabresa ("pool" Capsicum $s p)$, pimenta-de-jardim (C.annuum), pimenta dedo-de-moça (C. baccatum) e pimenta malagueta (C. frutescens), apresentaram atividades de inibição e inativação seletivas, em ordem decrescente, para salmonela, coliforme fecal, enterococo e estafilococo. As demais, pimenta cambuci $(C$. baccatum) e os pimentões (C. annuum) amarelo, verde e vermelho, apresentaram nenhuma atividade. Discute-se a validade da ferramenta etnográfica na prospecção de fatores de proteção anti-bacteriana em plantas, bem como a influência da inibição/inativação na preditividade do diagnóstico bacteriológico.
\end{abstract}

Palavras-chave: atividade antibacteriana, inibição bacteriana, inativação bacteriana, Capsicum sp., pimentas e pimentões

\begin{abstract}
In vitro antibacterial activity of hot and sweet peppers (Capsicum sp.) on four food toxinfective bacteria. The intensity of bacterial inhibition activity (INIB) and the intensity of bacterial inactivation activity (IINAB) of extracts of eight peppers of the genus Capsicum, ethnographically located in the metropolitan region of Porto Alegre, Rio Grande do Sul State, Brazil, were assessed in vitro through Dilution Tests in Multiple Tube Series against standardized bacterial inocula (American Type Culture Collection - ATCC), Staphylococcus aureus (25923), Enterococcus faecalis (19433), Salmonella enteritidis (13076), and Escherichia coli (11229), respectively, at challenge doses $=10^{7} \mathrm{CFU} \mathrm{mL}^{-1}$. Four of these species, cayenne pepper (Capsicum sp pool), garden pepper ( $C$. annuum), ají pepper (C. baccatum), and malagueta pepper ( $C$. frutescens), had selective inhibition and inactivation activities, in decreasing order, to salmonella, fecal coliforms, enterococcus and staphylococcus. The remaining ones, cambuci pepper ( $C$. baccatum) and yellow, green and red sweet peppers (C. annuum) had no activity. The validity of the ethnographic tool in the exploration of antibacterial protection factors from plants, as well as the influence of inhibition/inactivation in the bacteriological diagnosis predictability, is discussed.
\end{abstract}

Key words: antibacterial activity, bacterial inhibition, bacterial inactivation, Capsicum sp., hot and sweet peppers

\section{INTRODUÇÃO}

A importância das bactérias toxinfectivas em alimentos para a saúde coletiva permanece em evidência, considerando a resistência no meio

externo, mais especificamente em resíduos, dejetos, matérias primas alimentares para consumo humano e animal, solo e águas de abastecimento,

Recebido para publicação em 07/05/2008

Aceito para publicação em 01/08/2009

Rev. Bras. PI. Med., Botucatu, v.12, n.1, p.8-12, 2010. 
manifestando-se tanto individualmente como em centenas ou milhares de indivíduos através de surtos. Muitas vezes a incidência e o isolamento são de difícil avaliação, considerando as deficiências da vigilância epidemiológica e a relação com a notificação, o que não impede o aumento significativo do número de focos constatados (Acha \& Szyfres, 2003).

$\mathrm{Na}$ epidemiologia e profilaxia de doenças transmissíveis, a pesquisa de fatores de proteção sustentável, mormente entre recursos naturais renováveis como plantas com indicativo medicinal, condimentar ou aromático, constitui prioridade segundo a orientação da Organização Mundial da Saúde/Conferências Mundiais de Saúde (Akerele, 1988, 1993; Organización Panamericana de la Salud, 1984, 1985, 1990), com ênfase aos aspectos culturais tradicionais envolvidos e a relação com a atenção básica.

As pimentas consideradas pungentes no gênero Capsicum são reconhecidas pelos teores de vitaminas, minerais, pigmentos naturais e pela sensorialidade, esta associada às concentrações de capsaicina. O composto químico capsaicina (8-metil$\mathrm{N}$-vanilil 1-6-nonamida) é o componente ativo dessas pimentas conhecidas internacionalmente como pimentas chili ou ardidas. É irritante para os mamíferos, incluindo os humanos, e produz sensação de queimação em qualquer tecido que entre em contato (Perucka \& Materska, 2001).

Takikawa et al. (2002) afirmam que, a capsaicina e diversos componentes correlatos são conhecidos como capsaicinóides, sendo produzidos como metabólito secundário pelas pimentas do gênero Capsicum, provavelmente como barreiras contra herbívoros, classificando as diferentes espécies quanto aos teores de capsaicina, destacando $C$. frutescens (pimenta malagueta) com 0,89\%, C. baccatum (pimentadedo-de-moça) com 0,48\%, C. annuum (pimenta-dejardim) com 0,20\%, C. baccatum (pimenta cambuci) e os diferentes pimentões (C. annuum) com $0,0 \%$ do referido composto. Cruz et al. (2003) relacionam a pungência à concentração de capsaicina e à atividade antibacteriana dos extratos destas plantas.

Carvalho et al. (2006) demonstraram que bactérias toxinfectivas alimentares podem sofrer inibição pela presença de condimentos como soluções conservantes em alimentos, intervindo significativamente na preditividade dos resultados de pesquisa diagnóstica no sentido falso-negativo, mesmo obedecidas as determinações da legislação vigente.

O presente trabalho tem como objetivo determinar in vitro a Intensidade de Atividade de Inibição Bacteriana (IINIB) e de Inativação Bacteriana (IINAB) de diferentes espécies de pimentas do gênero Capsicum, acessadas na região metropolitana de Porto Alegre/RS/BR, avaliando a relação com a preditividade dos resultados de pesquisa diagnóstica destes agentes transmissíveis por alimentos.

\section{MATERIAL E MÉTODO}

Foram selecionadas amostras de pimentas do gênero Capsicum, de uso popular Capsicum annuum (pimentões amarelo, verde, vermelho e pimenta-de-jardim), Capsicum baccatum (pimenta cambuci e pimenta dedo-de-moça), Capsicum frutescens (pimenta malagueta), bem como, a pimenta calabresa ("pool" de Capsicum sp).

Todas as plantas foram acessadas na região metropolitana de Porto Alegre/RS/BR, identificadas botanicamente e encaminhadas como exsicatas (Ming, 1996) para registro no Herbário do Departamento de Botânica, do Instituto de Biologia da Universidade Federal do Rio Grande do Sul/RS/Brasil.

Os frutos dos diferentes acessos foram utilizados ainda frescos (maduros, recém colhidos), com exceção da pimenta calabresa, esta seca em estufa com ar circulante a $40^{\circ} \mathrm{C}$ e assim armazenada para uso posterior. Estes frutos foram submetidos aos processos de extração alcoólica (alcoolatura/ planta in natura), para obtenção das soluções antibacterianas, segundo Farmacopéia (1959). Desta forma, os frutos foram triturados grosseiramente e colocados em álcool etílico de cereais (Farmaquímica, Porto Alegre/RS/BR) a 96 GL, na proporção de 400 $\mathrm{g}$ de planta para $1000 \mathrm{~mL}$ de álcool. Após período de quinze dias, os extratos foram submetidos à destilação fracionada sob pressão reduzida em sistema rotaevaporador, desprezando-se a porção alcoólica e reidratando-se o extrato resultante com água destilada estéril, reconstituindo-se às concentrações iniciais de trabalho.

Foram desafiadas quatro linhagens bacterianas padrão American Type Culture Collection (ATCC), duas Gram-negativas: Salmonella enteritidis (ATCC 13076) e Escherichia coli(ATCC 11229) e duas Gram-positivas: Staphylococcus aureus (ATCC 25923) e Enterococcus faecalis (ATCC 19433). Estas linhagens pertenciam à bacterioteca do Laboratório de Higiene do Instituto de Ciência e Tecnologia de Alimentos (ICTA/UFRGS), sendo ativadas especificamente para este estudo, em meio $\mathrm{BHI}$ (Brain Hearth Infusion - DIFCO ${ }^{\circledR}$ ) à $37^{\circ} \mathrm{C}$ em aerobiose, atingindo concentrações mínimas de inóculo $=10^{8}$ UFC $\mathrm{mL}^{-1}$, entre 18 e 24 horas de incubação. A avaliação desta concentração inicial foi realizada através da técnica da microgota (Romeiro, 2007) e a contagem de microrganismos viáveis foi concretizada em placas de Petri contendo meio de cultura PCA (Plate Count Agar, HIMEDIA, Índia). Foram realizadas diluições seriadas, a partir do inóculo inicial, transferindo-se $1 \mathrm{~mL}$ deste para tubos de ensaio contendo $9 \mathrm{~mL}$ de água peptonada 0,1\% (BIOBRÁS, Montes Claros/MG/BR) para obter a diluição $10^{-1}$, e 
assim sucessivamente até a diluição $10^{-8}$. De cada diluição foram transferidas três gotas para placas de Petri utilizando micropipetas de $15 \mu \mathrm{L}$ e a leitura realizada em 24 horas de incubação aeróbia à $37^{\circ} \mathrm{C}$. $O$ valor final considerado constituiu-se da média das contagens das gotas triplicadas, avaliadas biometricamente segundo Cavalli-Sforza (1974).

Para a avaliação da atividade antibacteriana dos diferentes extratos estudados, lida como IINIB e IINAB, utilizaram-se os Testes de Diluição (DVG, 1981), com base na Técnica do Sistema de Tubos Múltiplos, referida por Souza \& Wiest (2007), Avancini \& Wiest (2008), Avancini et al. (2008) e Wiest et al. (2009), confrontando os extratos das diferentes espécies de Capsicum com diluições seriais logarítmicas $\left(10^{-1}\right.$ a $10^{-8}$ UFC mL-1) das bactérias padrões em teste, controlando o crescimento bacteriano por plaqueamento específico, bem como, prováveis contaminações intervenientes.

Entende-se por IINIB/bacteriostasia, o resultado do confronto da bactéria com a solução antibacteriana em meio específico, e por IINAB/ bactericidia, o mesmo resultado, porém sob a influência de desinibidores bacterianos como o polisorbato-80, a histidina e lecitina, entre outros, acrescidos ao BHI. Estes valores são representações da atividade biológica inibitória/bacteriostasia ou inativadora/bactericidia das diferentes soluções antibacterianas sobre os microrganismos. Desta maneira, atribuiu-se o valor máximo 8 (oito) quando a atividade de inibição ou de inativação de uma determinada concentração do extrato vegetal correspondeu à inibição ou inativação de $10^{-1}$ ou $10^{7}$ UFC $\mathrm{mL}^{-1}$ (partindo-se de uma cultura ativada com no mínimo $10^{8} \mathrm{UFC} \mathrm{mL}^{-1}$ ), ou valor 0 (zero) quando da verificação de nenhuma atividade, tanto de inibição como de inativação, demonstrada pela concentração do extrato vegetal em teste.

Em todos os testes avaliaram-se os resultados através de análise estatística descritiva e análise de variância, pelo teste de Fisher, segundo o programa Sisvar 5.0 (2007).

\section{RESULTADOE DISCUSSÃO}

Entre os oito acessos de pimentas da região metropolitana de Porto Alegre, Rio Grande do Sul, Brasil, quatro apresentaram alguma atividade antibacteriana, enquanto as demais apresentaram nenhuma atividade, nas condições dos diferentes experimentos (Tabela 1).

A análise estatística destes resultados revelou que a pimenta calabresa ("pool" de Capsicum $s p$.) não apresentou diferença significativa $(p<0,05)$

TABELA 1. Valores arbitrários da Intensidade de Atividade de Inibição e Intensidade de Atividade de Inativação produzidas in vitro por extratos de plantas do gênero Capsicum sobre diferentes padrões bacterianos, em 72 horas de incubação à $36^{\circ} \mathrm{C}$.

\begin{tabular}{|c|c|c|c|c|c|c|c|c|}
\hline \multirow{3}{*}{ Planta (extrato) } & \multicolumn{8}{|c|}{ Padrões bacterianos } \\
\hline & \multicolumn{2}{|c|}{ SA } & \multicolumn{2}{|c|}{ EF } & \multicolumn{2}{|c|}{ SE } & \multicolumn{2}{|c|}{ EC } \\
\hline & IINIE & IINAB & IINIB & IINAB & IINIB & IINAB & IINIB & IINAB \\
\hline Pimenta calabresa ("pool" de Capsicum) & 1 & 0 & 0 & 0 & 8 & 0 & 2 & 1 \\
\hline Pimenta dedo-de-moça (C. baccatum L.) & 4 & 2 & 0 & 0 & 8 & 6 & 5 & 2 \\
\hline Pimenta de jardim (C. annuum L.) & 2 & 2 & 2 & 0 & 5 & 3 & 3 & 0 \\
\hline Pimenta malagueta ( $C$. frutescens $\mathrm{L}$.) & 3 & 2 & 6 & 6 & 8 & 8 & 8 & 0 \\
\hline Pimenta cambuci (C. baccatum L.) & 0 & 0 & 0 & 0 & 0 & 0 & 0 & 0 \\
\hline Pimentão amarelo (C. annuum L.) & 0 & 0 & 0 & 0 & 0 & 0 & 0 & 0 \\
\hline Pimentão verde (C. annuum L.) & 0 & 0 & 0 & 0 & 0 & 0 & 0 & 0 \\
\hline Pimentão vermelho (C. annuum L.) & 0 & 0 & 0 & 0 & 0 & 0 & 0 & 0 \\
\hline
\end{tabular}

$\mathrm{SA}=$ Staphylococcus aureus; $\mathrm{EF}=$ Enterococcus faecalis; SE = Salmonella enteritidis; $\mathrm{EC}=$ Escherichia coli. Valores de 1(um) a 8 (oito) indicam a mínima e a máxima atividade antibacteriana em IINIB (Intensidade de atividade de inibição e IINAB (Intensidade de atividade de inativação); Valor 0 (zero) indica ausência de atividade 
frente a $S$. aureus e $E$. faecalis, tanto em IINIB como em IINAB; frente a $S$. enteritidis e $E$. coli, estas apresentaram diferença significativa entre si $(p>0,05)$ e entre as demais bactérias testadas; $S$. enteritidis por sua vez apresentou diferença significativa comparando-se IINIB e IINAB. Quanto a pimenta-dedode-moça ( $C$. baccatum) os resultados apresentaram diferenças $(p>0,05)$ significativas entre todas as bactérias bem como entre IINIB e IINAB das mesmas, com exceção da salmonela, ressaltando a inativação de $10^{5}$ UFC $\mathrm{mL}^{-1}$ desta bactéria.

Para a pimenta-de-jardim (C.annuum) $S$. aureus, E. faecalis e E. coli não apresentaram diferenças significativas entre si $(p<0,05)$ destacandose novamente a Salmonella ( $p>0,05)$, esta também apresentando diferença significativa entre IINIB e IINAB. Frente a pimenta malagueta ( $C$. frutescens), os inóculos padrões de $E$. faecalis, $S$. Enteritidis e E. coli não apresentarem diferença significativa $(p<0,05)$, enquanto, $S$. aureus diferenciou-se significativamente $(p>0,05)$ quando comparado às demais bactérias. Considerando os graus arbitrários atribuídos. a pimenta malagueta inativou $E$. faecalis na concentração de $10^{5}$ UFC mL-1, bem como, $S$.

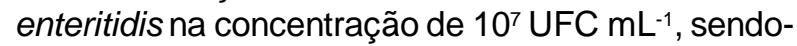
Ihe atribuído grau máximo 8 (oito).

Especificamente em relação a $S$. aureus, não se verificou diferença significativa $(p<0,05)$ entre as plantas testadas com alguma atividade. Em relação ao $E$. faecalis não houve diferença significativa para as pimentas calabresa, dedo-de-moça e de-jardim, embora apresentando diferença muito significativa $(p=0,01)$ para a pimenta malagueta. Em relação a $S$. enteritidis não houve diferença significativa entre as plantas que apresentaram alguma atividade. Quanto a $E$. coli houve diferença significativa para todas as plantas $(p>0,05)$ sendo que a diferença mais significativa $(p=0,01)$ foi revelada pela pimenta malagueta.

Os acessos de $C$. annuum (pimenta cambuci) e $C$. annuum (pimentões amarelo, verde e vermelho) não apresentaram atividade alguma.

Os resultados deste trabalho coincidem, portanto, com as observações de Perucka \& Materska (2001), Takikawa et al. (2002) e Cruz et al. (2003) no que referem a atividade antibacteriana relacionada à pungência ou concentração de capsaicina destas plantas.

Especificamente dentre as pimentas estudadas, destacam-se a pimenta malagueta $(C$. frutescens) e "pimenta-calabresa" (pool de Capsicum $s p)$ por apresentarem inibição grau máximo oito (bacteriostasia), porém inativação grau mínimo zero (bactericidia) sobre E. coli e $S$. enteritidis, respectivamente. À luz desta constatação, colocase em discussão o risco da baixa preditividade dos resultados negativos de pesquisa destas duas bactérias, quando do diagnóstico em alimentos condimentados pelas pimentas citadas, durante investigações epidemiológicas de surtos de toxinfecções alimentares. O não crescimento bacteriano, ou a ausência de manifestação de bactérias viáveis nos testes atualmente recomendados, deveriam ser interpretados como resultados falsos-negativos, em função da bacteriostasia/inibição (IINIB) demonstrada, e não como resultados negativos-verdadeiros, ou mesmo positivos-verdadeiros, em função de bacteriocidia/ inativação (IINAB), pretendidos.

As diretrizes estabelecidas pela Wold Health Organization (1967), descritas por Bryan et al. (1987) e retomadas por Pinto \& Bergmann (2002), para a investigação de surtos toxinfectivos alimentares, não prevêem, rotineiramente, questionamentos sobre possível condimentação dos alimentos envolvidos em surtos toxinfectivos sob investigação. Considerando os presentes resultados, poderiam ser acrescidas no inquérito epidemiológico, informações sobre condimentação, aromatização, práticas de gastronomia étnica, entre outras, pertinentes a crescente complexidade dos sistemas de alimentação e nutrição. Estas informações orientariam o acréscimo de desinibidores bacterianos aos testes diagnósticos oficiais, principalmente quando negativos, apesar de evidências epidemiológicas advindas de dados, como taxa de ataque por alimento, sinais e sintomas prevalentes, período de incubação entre outros, garantindo, desta forma, a preditividade destes testes no sentido dos resultados falsosnegativos. Concretamente, um laudo com ausência de Salmonella em $25 \mathrm{~g}$ de um determinado alimento condimentado com Capsicum, desenvolvido sem a presença dos desinibidores anteriormente referidos nos testes diagnósticos, poderia indicar, com alta probabilidade, somente bacteriostasia/inibição bacteriana, resultado falso-negativo, ausência somente aparente da bactéria no alimento sob análise.

\section{CONCLUSÃO}

A pimenta malagueta ( $C$. frutescens) revelou a maior eficácia antibacteriana dentre as pimentas testadas. S. aureus revelou-se a bactéria mais resistente, enquanto $S$. Enteritidis revelou-se a mais sensível.

Os resultados permitem concluir, outrossim, nas condições do experimento, que as pimentas pungentes podem constituir fator de proteção quando agregados às formulações e preparações alimentares. Esta condimentação poderá interferir, por sua vez, na preditividade diagnóstica de surtos toxinfectivos envolvendo estes alimentos, confundindo-se aparente inativação com inibição bacteriana. 


\section{AGRADECIMENTO}

Ao CNPq (Conselho Nacional de Desenvolvimento Científico e Tecnológico/Brasil) pelo estímulo e financiamento contínuos.

\section{REFERÊNCIA}

ACHA, P.N.; SZYFRES, B. Zoonosis and communicable diseases common to men and animals: bacteriosis and mycosis. 3.ed. Washington: World Health Organization, 2003. 398p. (Cientifical and Technical Publication, n. 580) AKERELE, O. Las plantas medicinales: un tesoro que no debemos desperdiciar. Foro Mundial de la Salud, v.14, p.390-5, 1993.

AKERELE, O. Medicinal plants and primary health care: a agend for action. Fitoterapia, v. 59, n.5, p.355-63, 1988. AVANCINI, C.A.M.; WIEST, J.M. Atividade desinfetante do decocto de Hypericum caprifoliatum Cham. e Schlecht. - Guttiferae (escadinha, sinapismo), frente diferentes doses infectantes de Staphylococcus aureus (agente infeccioso em mastite bovina). Revista Brasileira de Plantas Medicinais, v.10, n.1, p.64-9, 2008.

AVANCINI, C.A.M. et al. Antimicrobial activity of plants used in the prevention and control of bovine mastitis in southern Brazil. Latin American Journal of Pharmacy, v.27, n.6, p.894-9, 2008.

BRYAN, F.L. et al. Procedures to investigate foodborne illness. 4.ed. lowa: International Association of Milk, Food and Environmental sanitarians, 1987. 47p.

CARVALHO, H.H.C.; WIEST, J.M.; GRECO, D.P. Atividade antibacteriana e a preditividade do condimento Artemisia dracunculus Linn. (Asteraceae), variedade inodora estragão - frente a Salmonella sp. Ciência e Tecnologia de Alimentos, v.26, n.1, p.75-9, 2006.

CAVALI-SFORZA, L. Biometric. Stuttgart: GustavFisher, 1974. p.201-4.

CRUZ, F.T. et al. Avaliação da atividade antibacteriana de diferentes pimentas e pimentões do gênero Capsicum e sua relação com o teor de capsaicinóides. In: SALÃO DE INICIAÇÃO CIENTÍFICA, 15., 2003, Porto Alegre. Anais... Porto Alegre: Editora da Universidade, 2003. p.205-6.

DVG - DEUTSCHE VETERINÄRMEDIZINISCHE GESELLSCHAFT. Richtlinien zur Prüfung chemischer Desinfektionsmittel für die Veterinärmedizin/ Normas para testagem de desinfetantes químicos para a medicina veterinária. In: SCHLIESSER, T.; STRAUCH, $D$. Desinfektion in Tierhaltung, Fleisch- und Milchwirtschaft/Desinfecção na produção animal, em laticínios e em frigoríficos. Stuttgart: Enke Verlag, 1981. p.47-55.

FARMACOPÉIA dos Estados Unidos do Brasil. 2.ed. São Paulo: Siqueira, 1959. 532p.

MING, L.C. Coleta de plantas medicinais. In: DI STASI, L.C. Plantas medicinais arte e ciência: um guia de estudo interdisciplinar. São Paulo: UNESP, 1996. p.6986.

ORGANIZACIÓN PANAMERICANADE LASALUD (OPAS). Cultura medica tradicional. Boletin de la Oficina Sanitária Panamericana, v.96, n.2, p.180-1, 1984.

ORGANIZACIÓN PANAMERICANADE LASALUD (OPAS). Cultura medica tradicional. Boletin de la Oficina Sanitária Panamericana, v.98, n.4, p.373-7, 1985.

ORGANIZACIÓN PANAMERICANADE LASALUD (OPAS). Cultura medica tradicional. Boletin de la Oficina Sanitária Panamericana, v.108, n.1, p.77-80, 1990.

PERUCKA, I.; MATERSKA, M. Phenylalanine ammonialyase and antioxidant activities of lipophilic fraction of fresh pepper fruits Capsicum annuum L. Innovative Food Science \& Emerging Technologies, v.2, n.2, p.189-92, 2001.

PINTO, A.; BERGMANN, G.P. Investigação de enfermidades transmitidas por alimentos. Higiene Alimentar, v.14, n.74, p.21-4, 2002.

ROMEIRO, R.S. Técnica de microgota para contagem de células bacterianas viáveis em uma suspensão. Laboratório de Bacteriologia de Plantas. Viçosa: UFV. Disponível em: <http://www.ufv.br/dfp/bac/uni9.pdf>. Acesso em: 23 mar. 2007.

SISVAR 5.0. Softwares Downloads. Disponível em: $<$ http://www.dex.ufla.br/ danielff/ softwares.htm>. Acesso em: 23 set. 2007.

SOUZA, A.A.; WIEST, J.M. Atividade antibacteriana de Aloysia gratissima (Gill et Hook)Tronc. (garupá, ervasanta) usada na medicina tradicional no Rio Grande do Sul-Brasil. Revista Brasileira de Plantas Medicinais, v.9, n.3, p.23-9, 2007.

TAKIKAWUA, A. et al. Antimicrobial activity of Nutmeg agaist Escherichia coli 0157. Journal of Bioscience and Bioengineering, v.94, n.4, p.3315-20, 2002.

WIEST, J.M. et al. Salmonella sp: inibição e inativação in vitro de extratos de plantas com indicativio etnográfico medicinal ou condimentar, acessadas em Porto Alegre /RS/BR. Arquivo Brasileiro de Medicina Veterinária e Zootecnia, v.61, p.132-9, 2009.

WORLD HEATH ORGANIZATION - WHO. Procedimientos para la investigación de bordes de enfermidades transmitidas por los alimentos. 2.ed. Washington: OPA OMS, 1967. 40p. 